\title{
CALCIUM CHANNEL BLOCKER AND RENAL MITOCHONDRIAL FUNCTION IN WARM RENAL ISCHEMIA
}

\author{
SILVIO TUCCI JR, TIAGO J. BORELLI-BOVO, ADAUTO J. COLOGNA, RICARDO B. \\ TIRABOSCHI, ANTONIO C.P. MARTINS, JOSE E.S. ROSELINO \\ Laboratory of Experimental Surgery, Department of Surgery and Anatomy, Ribeirao Preto School of \\ Medicine, University of Sao Paulo, Ribeirao Preto, Brazil
}

\begin{abstract}
Objective: Ions, particularly calcium ions, play an important role in ischemia-reperfusion cell injury. In this study, we investigated the action of verapamil on the mitochondrial function of kidneys submitted to ischemia without blood reperfusion in order to study isolated early and late ischemic effects.

Materials and Methods: 44 rats were submitted to bilateral warm renal ischemia for $30 \mathrm{~min}$ utes. The kidneys were then immediately reperfused with saline or Euro-Collins (EC) solution, with and without previous administration of $0.35 \mathrm{mg} / \mathrm{kg}$ of verapamil. Mitochondrial function was assessed at the end of renal perfusion and after 24 hours of cold preservation.

Results: In kidneys perfused with saline, verapamil allowed a significant early preservation of state III mitochondrial respiration, a result that was no longer evident after 24 hours. In kidneys perfused with EC solution, verapamil did not change state III for either early or late evaluations. Comparison of the groups showed that the results obtained for kidneys perfused with EC were always superior to those obtained for the saline group, except for the initial analysis of kidneys treated with saline and verapamil, which showed results similar to those obtained with EC perfusion alone.

Conclusion: Administration of verapamil before warm ischemia provides partial and shortlasting functional protection of the mitochondrial function in kidneys perfused with sodium rich saline. With Euro-Collins solution, verapamil did not show any additional beneficial effect. This fact permits us to conclude that protective action is effective only under conditions that facilitate increased sodium uptake and/or potassium loss.
\end{abstract}

Key words: kidney; mitochondria; ischemia; function; verapamil

Int Braz J Urol. 2005; 31: 384-9

\section{INTRODUCTION}

Despite the care taken to preserve vital functions in brain dead patients and candidates for organ donation, organs removed from them may pass through a variable period of hypoxia and/or ischemia secondary to a low renal blood flow with a conse- quent deleterious effect on renal cell metabolism that may affect function after transplantation (1).

In an attempt to reduce renal cell damage, kidney preservation for transplantation currently consists of arterial perfusion with solutions whose composition is similar to that of the intracellular medium used at low temperature. Hypothermia is mandatory 
because it decreases the cellular metabolic rate, reducing the renal oxygen demand by $84 \%$ at $20^{\circ} \mathrm{C}$ and by $95 \%$ at $10^{\circ} \mathrm{C}(2)$.

In addition of hypothermia and different preservation solutions, several drugs have been used to maintain cell integrity and to preserve the organs for transplantation $(3,4)$. Among them, calcium channel blockers have shown reduction of cell damage induced by oxygen deprivation. Verapamil has shown a protective effect on renal function in animal models, specifically acute ischemic renal failure when administered before an ischemic episode ranging from 40 to 60 minutes, usually with blood reperfusion after the period of ischemia (5-9), as well as in renal transplantation (10). In addition, there is an anti-oxidant protective effect against tissue injury attributable to oxidative stress (11).

Considering these aspects, the objective of the present study was to assess the action of verapamil on the mitochondrial function in kidneys of rats submitted to 30 minutes of warm ischemia and then immediately perfused with two different solutions at low temperature with no blood reperfusion of the kidney in order to study isolated early and late ischemic effects.

\section{MATERIALS AND METHODS}

This study was approved by the Institution Committee on Animal Research, following the recommendations for animal research by the National Institute of Health.

Forty-four male Wistar rats weighing 300 to $345 \mathrm{~g}$ were used. Of these, 37 underwent bilateral warm renal ischemia and were divided into 4 groups (A, B, C and D).

Warm renal ischemia: after thionembutal anesthesia (40 mg/kg, intra-peritoneal) and laparotomy, the aorta and vena cava were dissected and renal arterial blood flow was interrupted for 30 minutes by placing vascular clamps in the aorta above the emergence of the renal arteries. Groups B and D animals received $0.35 \mathrm{mg} / \mathrm{kg}$ of verapamil intravenously 15 minutes before the beginning of ischemia. After that, the aorta and the vena cava were ligated above and below the renal vessels. A small incision was made in the vena cava and in situ renal perfusion was started with $20 \mathrm{~mL}$ of a solution stored on ice and slowly injected by puncturing the aorta. The injected solution varied between groups, as described below. The incision in the vena cava permitted the drainage of blood and perfusion fluid. One of the kidneys was then randomly removed in order to obtain mitochondria and determine their function. The contralateral kidney was removed and kept in a flask immersed in ice $\left(0\right.$ to $\left.4^{\circ} \mathrm{C}\right)$, which contained the solution with which the kidney had been perfused. This organ was used 24 hours later for a new determination of mitochondrial function.

Perfusion solutions: Groups A $(\mathrm{n}=8)$ and $\mathrm{B}$ $(\mathrm{n}=5)$ - saline $(0.9 \% \mathrm{NaCL})$; Groups $\mathrm{C}(\mathrm{n}=12)$ and $\mathrm{D}(\mathrm{n}=12)$ - Euro-Collins ${ }^{\circledR}$ solution. Seven additional rats were used for the determination of control mitochondrial function. Euro-Collins was used in this study due to its frequent use as the main solution for organ perfusion in cadaveric and live donor kidney transplant at our institution.

Determination of mitochondrial function: to obtain the mitochondrial fraction, the kidney is washed in $0.9 \%$ saline solution conserved on ice and then fragmented in appropriate medium $(0.25 \mathrm{M}$ sucrose, $1 \mathrm{mM}$ EDTA, $1 \mathrm{mg} / \mathrm{mL}$ albumin, $\mathrm{pH}$ 7.4) using a Potter Elvehjem blender 3 times for 3 seconds at 1 minute intervals. The fraction containing the mitochondria is obtained by centrifugation of this tissue, first at $750 \mathrm{x} g$ for 3 minutes, and then twice at $15000 \mathrm{x} \mathrm{g}$ for 10 minutes. All centrifugations were done at $4^{\circ}$ Celsius. A Himac CR21 refrigerated Hitachi ${ }^{\circledR}$ centrifuge was used. The final precipitate was suspended and used to determine the protein content and the respiratory activity of mitochondria. The protein concentration was assayed by means of the biuret modified reaction $(12,13)$. The polarographic method involving oxygen electrodes using a Gilson oxygraph was applied to determine the respiratory activity of mitochondria (14).

The parameters of mitochondrial function studied were state III (oxygen consumption in the presence of ADP) and state IV (basal respiration after the mitochondria had converted to ATP all the ADP available in the assay). With these two parameters, the respiratory control ratio (RCR) was calculated for 
each respiratory assay. This ratio measures the coupling of oxidative phosphorylation and is used as the quality control of the mitochondrial preparation. In the present study, the only data used were obtained in the experiments in which the RCR of the control mitochondrial preparation presented a value higher than 3.5.

The paired and unpaired Student t-test was used for parametrical variables and the WilcoxonMann-Whitney test for non-parametric variables, with level of significance set at $5 \%$.

\section{RESULTS}

Data of mitochondrial function obtained for 73 organs were used, considering the mitochondrial $\mathrm{RCR}$ as the quality control of the preparations.

Kidneys perfused with saline and verapamil showed a significant preservation of state III mitochondrial respiration in the evaluation performed immediately after the perfusion period when compared with kidneys without verapamil $(\mathrm{p}<0.05)$. However, this difference was not observed after 24 hours of cold kidney preservation.
In organs perfused with Euro-Collins ${ }^{\circledR}$ solution, the administration of verapamil before ischemia did not significantly alter the state III values either at the immediate or at the 24-hour evaluation periods. However, there was a tendency to higher values of these parameters in the animals that received this drug.

When the groups were compared, the results obtained after perfusion with Euro-Collins ${ }^{\circledR}$ solution were always superior to those obtained for the kidneys perfused with saline ( $\mathrm{p}<0.05)$, except for the animals which received verapamil in combination with saline, whose results were similar to those obtained with perfusion of Euro-Collins ${ }^{\circledR}$ alone $(\mathrm{p}>0.05)$.

State III and RCR values are listed in Table-1.

\section{COMMENTS}

In aerobic organisms, oxidative phosphorylation is the major source of ATP for all vital processes needing a supply of chemical energy. The variation in free energy to maintain these processes originates from carbon substrates and from the correspond-

Table 1 - Data concerning state III of mitochondrial respiration and respiratory control ratio (RCR) (mean \pm standard error).

\begin{tabular}{lccc}
\hline Experimental Groups & Time & State III & RCR \\
\hline A $(\mathrm{S})$ & I & $130^{* * * * \pm 11.7}$ & $3.17 \pm 0.38$ \\
& L & $163.2 * * \pm 12.5$ & $2.47 \pm 0.33$ \\
B $(\mathrm{S}+\mathrm{V})$ & I & $256.8^{*} \pm 5.8$ & $3.97 \pm 0.40$ \\
& L & $184.7^{* *} \pm 10.2$ & $2.55 \pm 0.38$ \\
C (EC) & I & $235.1 \pm 12.7$ & $4.77 \pm 0.57$ \\
& L & $229.6 \pm 17.1$ & $3.75 \pm 0.28$ \\
D (EC + V) & I & $278.1 \pm 17.8$ & $3.65 \pm 0.38$ \\
& L & $270.0 \pm 15.2$ & $4.87 \pm 0.43$ \\
Control & & $390 \pm 7.8$ & $5.21 \pm 0.71$ \\
\hline
\end{tabular}

$p<0.05$ - level of significance; * saline group difference with/without verapamil, ** different from Euro-Collins group in the same experimental condition. $I=$ evaluation at the end of perfusion, $L=$ evaluation 24 hours after perfusion, $S=$ saline, EC $=$ Euro-Collins ${ }^{\circledR}$ solution, $V$ = verapamil. State III data are reported as nAtoms $\mathrm{O}_{2} / \mathrm{min}$. $\mathrm{mg}$ prot. 
ing electron transport in the respiratory chain that occurs inside the mitochondrial membrane. Oxygen is required as the final electron receptor for the maintenance of these metabolic processes. During ischemia, anoxia prevents this efficient form of ATP production, consequently impairing cell functions.

The cause-effect relationship between the processes for obtaining chemical energy is still quite obscure and depends on membrane integrity (such as integrity of the mitochondrial membrane) and on renal function, which depends on cell organization. In the kidney, one of the consequences of ischemia is the loss of tubular cell polarity and the redistribution of the $\mathrm{Na}^{+}, \mathrm{K}^{+}$ATPase enzyme, which represents cellular disorganization and compromises renal function. The relation of this disorganization to the fall in ATP levels has been proposed by other investigators (15). In the absence of oxygen, the anaerobic glycolytic pathway is activated, with glycogen degradation, lactate and $\mathrm{H}^{+}$production, increase in the number of particles with a consequent increase in osmotic pressure, and development of cellular edema $(16,17)$. Not only the lack of oxygen but also the interruption of tissue removal of metabolites contributes to this condition.

Several studies have indicated an important contribution of calcium ion to cell damage in the process of renal ischemia-reperfusion $(18,19)$. Usually, the rapid accumulation of $\mathrm{H}^{+}$permits the exchange of this ion with $\mathrm{Na}^{+}$and concomitantly the exchange of $\mathrm{Na}^{+}$with $\mathrm{Ca}^{++}$. The ion calcium activates phospholipases and proteases $(17,20)$ and a further increase in plasma membrane permeability with a massive calcium influx into the cytoplasmic and the mitochondrial compartments. This process leads to irreversible cell injury.

The beneficial effects of verapamil in the processes of kidney ischemia-reperfusion have been demonstrated. However, this protection may be due both to its vasodilating action and to its effect as a calcium channel blocker (5). Electron microscopy studies have shown that verapamil also acts to preserve the ultra structure of the mitochondrial membrane (21), and possibly reducing the infiltration of neutrophils into the ischemic kidney (22). In the present study, we assessed the action of verapamil on the mitochondrial function of renal cells when administered in combination with two different perfusion solutions. Any vasodilating effect was excluded, since nephrectomy was performed with no blood reperfusion of the kidney.

The evaluation performed at the end of perfusion showed that in organs perfused with saline, the administration of verapamil before ischemia allowed a significant preservation of state III mitochondrial respiration compared to the group that did not receive the drug. This beneficial effect may correspond to the maintenance of structural membrane integrity observed by Alvarez et al. (21). In addition, the similarity in state III values for groups B and C $(p>0.05)$ in the evaluation performed immediately after nephrectomy suggest that the protection of the mitochondrial membrane provided by Euro-Collins ${ }^{\circledR}$ perfusion was qualitatively similar to that obtained with verapamil.

These data confirm the inadequacy of sodium saline solution alone for renal preservation (allowing for the manifestation of the action of verapamil) and, more importantly, indicate that the ionic effect, i.e., the short duration effect, may be exerted by both the verapamil and the Euro-Collins ${ }^{\circledR}$ solution. This suggests that the prevention of the sodium increase by $\mathrm{EC}$ is as beneficial as the initial prevention of the increase in calcium, without synergistic effects of the two maneuvers on prolonged preservation. In acute and short duration episodes of ischemia during which the effects of the changes in ATP levels affecting the functioning of the cellular ion pumps may be initially and partially prevented by the anaerobic production of ATP, the use of verapamil may permit renal membrane preservation in addition to preserving vascular endothelium obtained with the use of sodium rich saline (23)

The disappearance of the protective effect of verapamil on organs assessed 24 hours after renal perfusion with saline may suggest that the action of the drug is short lasting, or that blockade of calcium entry by verapamil occurs only initially. Thus, if sodium continues to be offered through the $0.9 \%$ saline solution, the ischemic injury will increase and cell and mitochondrial function will fall over time even under conditions of hypothermia. 
The results obtained for the kidneys perfused with the Euro-Collins ${ }^{\circledR}$ solution showed higher values of state III mitochondrial respiration after previous administration of verapamil. These values did not reach a statistically significant level, but may indicate a protective tendency of the drug in addition to that provided by the Euro-Collins ${ }^{\circledR}$ solution. The analysis performed after 24 hours of cold ischemia revealed the persistence of this tendency and favors the hypothesis that the results obtained for the group perfused with saline solution may really represent a worsening of cell injury. It should be pointed out that by not permitting renal reperfusion, we limited the action of verapamil exclusively to the period of ischemia.

This aspect of the experimental design permits us to exclude from the discussion some blocking action of the drug on the calcium elicited phenomena and its eventual vasodilating effects that might be observed at the time of reperfusion. Administration of verapamil before warm ischemia provides partial- and short-lasting functional protection of the mitochondrial fraction in kidneys perfused with sodium rich saline. When the kidneys were perfused with Euro-Collins ${ }^{\circledR}$, a high potassium solution similar to the intracellular medium, verapamil did not show any additional beneficial effect. This fact allows for the conclusion that the protective action of verapamil is effective only under conditions that facilitate increased sodium uptake and/or potassium loss.

Values of state III mitochondrial respiration closer to those observed in controls suggest that the mitochondrial membranes were functionally more efficient with a greater capacity for synthesis, and therefore were able to re-establish, at least theoretically, ATP stores after organ reperfusion, contributing to the return of cell function.

Recently, the study of prolonged periods of total ischemia in skeletal muscle whose dimensions were maintained in order to preserve energy metabolism $(24,25)$ showed that the variation in state III respiration was a more sensitive indicator of mitochondrial damage than the membrane potential, basal mitochondrial respiration (state IV), or RCR (25). However, the last index (RCR) still seems to represent a relatively simple and reliable form of evaluating the quality of mitochondrial preparations.

In conclusion, analysis of these results as a whole indicates that the administration of verapamil before the ischemic episode provides only partial- and short-lasting functional protection of mitochondrial function and this protection is superimposed on that promoted by renal perfusion with Euro-Collins ${ }^{\circledR}$ solution before ischemia. On the other hand, early events occurring during the initial period of ischemia may include a possible direct sodium effect upon mitochondrial function. Therefore, this possibility may deserve further investigation when the role of kidney function upon ionic homeostasis is taken into account.

\section{REFERENCES}

1. Paller MS: The cell biology of reperfusion injury in the kidney. J Investig Med. 1994; 42: 632-9.

2. Marshall VC, Jablonsky P, Scott DF: Renal Preservation. In: Morris, PJ (ed.), Kidney Transplantation. Principles and Practice. 4th ed., Philadelphia, WB Saunders. 1994; pp. 86-108.

3. Ametani MS, Southard JH, Belzer FO: Importance of glutathione and adenosine in cold storage of the kidney. Transplant Proc. 1990; 22: 469-71.

4. Cejalvo D, Lloris-Carsi JM, Toledo-Pereyra LH, Calvo MA: Effect of adenosine and allopurinol on liver ischemia-reperfusion. Transplant Proc. 1993; 25: 30234.

5. Malis CD, Cheung JY, Leaf A, Bonventre JV: Effects of verapamil in models of ischemic acute renal failure in the rat. Am J Physiol. 1983; 245: F735-42.

6. Goldfarb D, Iaina A, Serban I, Gavendo S, Kapuler S, Eliahou HE: Beneficial effect of verapamil in ischemic acute renal failure in the rat. Proc Soc Exp Biol Med. 1983; 172: 389-92.

7. Burke TJ, Arnold PE, Gordon JA, Bulger RE, Dobyan DC, Schrier RW: Protective effect of intrarenal calcium membrane blockers before or after renal ischemia. Functional, morphological, and mitochondrial studies. J Clin Invest. 1984; 74: 1830-41.

8. Elkadi HK, Mardan AH, Nghiem DD, Southard JH: The role of calcium antagonists in the management of renal warm ischemia. J Urol. 1989; 141: 974-80.

9. Dosluoglu HH, Aktan AO, Yegen C, Okboy N, Yalcm AS, Yahn R, et al.: The cytoprotective effects of verapamil and iloprost (ZK 36374) on ischemia/ 
reperfusion injury of kidneys. Transpl Int. 1993; 6: 13842.

10. Dawidson I, Lu C, Palmer B, Peters P, Rooth P, Risser R, et al.: Verapamil (VP) improves the outcome after renal transplantation (CRT). Transpl Int. 1992; 5 (suppl 1): S60-2.

11. Guler C, Samli M, Aksoy Y, Demirbas M, Kilinc A, Ellidokuz E, at al.: Effects of carbon dioxide pneumoretroperitoneum on free radical formation in remote organs and use of verapamil as an antioxidant. J Endourol. 2004; 18: 245-9.

12. Gornall AG, Paller MS, David, MM: Determination of the serum proteins by means of the biuret reaction. J Biol Chem. 1949; 177: 751-66.

13. Kaplan RS, Pedersen PL: Characterization of phosphate afflux pathways in rat liver mitochondria. Biochem J. 1983; 212: 279-88.

14. Chance B, Willians GR: The respiratory chain and oxidative phosphorylation. Adv Enzymol Relat Subj Biochem. 1956; 17: 65-134.

15. Molitoris BA, Simon FR: Renal cortical brush-border and basolateral membranes: cholesterol and phospholipid composition and relative turnover. J Membr Biol. 1985; 83: 207-15.

16. Jones DP: Renal metabolism during normoxia, hypoxia, and ischemic injury. Annu Rev Physiol. 1986; 48: 33-50.

17. Brezis M, Epstein FH: Cellular mechanisms of acute ischemic injury in the kidney. Annu Rev Med. 1993; 44: 27-37.
18. Paller MS, Greene EL: Role of calcium in reperfusion injury of the kidney. Ann N Y Acad Sci. 1994; 723: 59-70.

19. Farber JL, Chien KR, Mittnacht S Jr: The pathogenesis of irreversible cell injury in ischemia. Am J Pathol. 1981; 102: 271-81.

20. Sutton TA, Molitoris BA: Mechanisms of cellular injury in ischemic acute renal failure. Semin Nephrol. 1998; 18: 490-7.

21. Alvarez A, Martul E, Veiga F, Forteza J: Functional, histologic and ultrastructural study of the protective effects of verapamil in experimental ischemic acute renal failure in the rabbit. Ren Fail. 1994; 16: 193207.

22. Lopez-Neblina F, Paez-Rollys AJ, Toledo-Pereyra LH: Mechanism of protection of verapamil by preventing neutrophil infiltration in the ischemic rat kidney. J Surg Res. 1996; 61: 469-72.

23. Evora PR, Pearson PJ, Schaff HV: Crystalloid cardioplegia and hypothermia do not impair endotheliumdependent relaxation or damage vascular smooth muscle of epicardial coronary arteries. J Thorac Cardiovasc Surg. 1992; 104: 1365-74.

24. Xavier AR, Roselino JE, Resano NM, Garofalo MA, Migliorini RH, Kettelhut Ido C: Glyconeogenic pathway in isolated skeletal muscles of rats. Can J Physiol Pharmacol. 2002; 80: 164-9.

25. Brandao ML, Roselino JE, Piccinato CE, Cherri J: Mitochondrial alterations in skeletal muscle submitted to total ischemia. J Surg Res. 2003; 110: 235-40.

Received: February 24, 2005 Accepted after revision: June 15, 2005

\section{Correspondence address:}

Dr. Silvio Tucci Jr.

Departamento de Cirurgia e Anatomia

Faculdade de Medicina de Ribeirão Preto

Av. Bandeirantes, 3900, Campus USP

Ribeirão Preto, SP, 14049-900, Brazil

Fax: +55 16 633-2189

E-mail: stucci@convex.com.br 